\title{
Study the Effects of Communication Skills Training on Satisfaction and Anxiety Level of Dentistry Students and their Patients
}

\author{
Moosavi $\mathrm{H}^{*}$, Narimani $\mathrm{S}^{2}$ and Vosugh $\mathrm{I}^{3}$ \\ ${ }^{1}$ Associate Professor, Operative Dentistry, Dental Materials Research Center, Mashhad University of Medical \\ Sciences, Mashhad, Iran \\ ${ }^{2}$ Assistant Professor of Endodontics, Ardabil University of Medical Science, Ardabil, Iran \\ ${ }^{3}$ Assistant Professor of Psychiatry, Psychologists Consultants of Mashhad University of Medical Sciences, Iran
}

${ }^{*}$ Corresponding author: Moosavi H, Associate Professor, Operative Dentistry, Dental Materials Research Center, Mashhad University of Medical Sciences, Mashhad, Iran, Email: moosavih@mums.ac.ir

Citation: Moosavi H, Narimani S, Vosugh I (2015) Study the effects of communication skills training on satisfaction and anxiety level of dentistry students and their patients. J Dent Oral Care Med 1(3): 304. doi: $10.15744 / 2454-3276.1 .304$

Received Date: September 26, 2015 Accepted Date: November 05, 2015 Published Date: November 06, 2015

\begin{abstract}
Patient anxiety about the dental procedures is one of the most common problems in this profession. Most people avoid going to a dentist because of their fear and anxiety. The aim of this study was to examine the effects of communication skills training concerning satisfaction and anxiety level of dental students and their patients. The Ethics Committee of Mashhad University of Medical Sciences in Iran (no 86379) approved this study. In this controlled experimental clinical study, fifty-one last year dental students of Mashhad University and one hundred fifty-three patients were participated. Through use of an Anxiety standard questionnaire and school average of scores, data were collected about the level of satisfaction and anxiety and scientific and practical skills. Students of the experimental group took part in the communication skills workshop. The questionnaires were collected and because of ethic principles, participants were identified with numeric codes. Data were analyzed with t-test and Pearson correlation coefficient. There was a significant difference between satisfaction of interventional and control group. The communication skills workshop increased satisfaction of dental students $(p=0 / 024)$. There was a negative correlation between anxiety and satisfaction ( $\mathrm{p}$-value $=0.030, \mathrm{r}=0.305$ ). There was no significant difference between patients' satisfaction, patients' anxiety students' anxiety in the experimental and control group. Communication skills workshop increased the satisfaction of students but there was no effect on patients' satisfaction. There was a significant negative correlation between anxiety and satisfaction in both dental students and their patients. Communication skills increased the students' satisfaction, had an indirect effect on their anxiety level, and decreased it. Communication skills workshop is useful for dental students and their patient and would have good effects on doctor-patient correlation.
\end{abstract}

Keywords: Communication; Dental student; Satisfaction

\section{Introduction}

Patient anxiety about the dental procedures is one of the most common problems in this profession. Most people avoid going to a dentist because of their fear and anxiety [1]. One of the important things in dentistry is to control fear and anxiety of the patients. About 40 percent of people in western communities are concerned with the dentistry and 20 percent of them have severe fear [2,3]. Dentists deal with stressful things like needle, anxious patients and these all affect the dentists' rate of satisfaction and anxiety, what's more dentistry is a delicate job and doing things in the dark and small space of mouth with delicate instruments can be stressful for examiner and it is more horrible for students of dentistry and new graduates. Patient's satisfaction lead to their constant use of dentistry services and they use their doctors' instructions completely and the most important is that they are satisfied and this improve their psychological health, on the other hand satisfaction of dentist results in improvement the quality of the treatment and can increase patients' satisfaction indirectly $[1,4,5]$. Fear is the true primary evaluation of consequences; while anxiety is the mental status resulting from being worried [1]. The first step to cope with anxiety is to learn how the anxiety signs affect us. Mild and moderate anxiety helps us to overcome problems, however severe anxiety prevents normal functioning. Good doctor-patient relationship results in better efficiency and feeling between patient and doctor [5]. Surveys point that there is a significant relationship between individual communication skills of doctor and satisfaction of patient [6,7]. Improvement of doctor's communication skills increases the satisfaction of dentist and patient and its effect on anxiety of them is undeniable [8,9]. Non-pharmacological (behavioral and cognitive) techniques that can be used in the dental clinic or surgery in order to assist anxious individuals obtain needed dental care. Practical advice for managing anxious patients is provided and the evidence base for the various approaches is examined and summarized. The importance of firstly identifying dental fear and then understanding its etiology, nature and associated components is stressed. Anxiety management techniques range from good communication and establishing rapport to the use of systematic desensitization and hypnosis. Some techniques require specialist training but many others 
could usefully be adopted for all dental patients, regardless of their known level of dental anxiety. It is concluded that successfully managing dentally fearful individuals is achievable for clinicians but requires a greater level of understanding, good communication and a phased treatment approach. There is an acceptable evidence base for several non-pharmacological anxiety management practices to help augment dental practitioners providing care to anxious or fearful children and adults [10]. The aim of this study was to examine the effects of communication skills training concerning satisfaction and anxiety level of dental students and their patients.

\section{Material and Method}

The Ethics Committee of Mashhad University of Medical Sciences in Iran (no 86379) approved this study. In this con-trolled experimental clinical study, fifty-one last year dental students of Mashhad University and one hundred fifty-three patients were participated. Twenty-six of students were female and twenty-five were male. Male and female patients were almost equal (eighty female and seventy-three male). First, students were divided into two groups, control and experimental. Through use of an Anxiety standard questionnaire and school average of scores, data were collected about the level of satisfaction and anxiety and scientific and practical skills. Students of the experimental group took part in the communication skills workshop. The workshop was held two times. A psychologist taught communication skills to students of experimental group, then satisfaction, and anxiety questionnaires were given to students and their patients. The questionnaires used in study were extracted from standard questionnaires in the field of dental satisfaction and anxiety. Experts confirmed the reliability $(\alpha=0.74)$ and validity of the questionnaires. In the students' satisfaction and anxiety questionnaires, questions were about the satisfaction and anxiety during the dental procedures and in the patients' satisfaction and anxiety questionnaires, questions were about the different dental therapeutic conditions. For each one the scores were from one to four or five (Table 1).

\begin{tabular}{|c|c|c|c|c|}
\hline Dentist Satis & Questior & & & \\
\hline - The meetin & he patient & feel? & & \\
\hline$\square$ Very low & $\square$ Low & $\square 3$ Average & $\square$ High & $\square$ Very much \\
\hline - Their skills & ion to the & lo you assess th & ting? & \\
\hline$\square$ Very low & $\square$ Low & $\square 3$ Average & $\square$ High & $\square$ Very much \\
\hline - The level of & satisfactic & d you assess th & ing? & \\
\hline$\square$ Very low & $\square$ Low & $\square 3$ Average & $\square$ High & $\square$ Very much \\
\hline - Your satisfa & of the the & & & \\
\hline$\square$ Very low & $\square$ Low & $\square 3$ Average & $\square$ High & $\square$ Very much \\
\hline Dental Anxi & entory: & & & \\
\hline Please detern & best opti & bes your feelin & the cross mark. & \\
\hline - I feel calm. & & & & \\
\hline$\square$ Very low & $\square$ Low & $\square$ High & $\square$ Too high & \\
\hline - I feel safe. & & & & \\
\hline$\square$ Very low & $\square$ Low & $\square$ High & $\square$ Too high & \\
\hline - I feel like I' & cess. & & & \\
\hline$\square$ Very low & $\square$ Low & $\square$ High & $\square$ Too high & \\
\hline - I feel relieve & & & & \\
\hline$\square$ Very low & $\square$ Low & $\square$ High & $\square$ Too high & \\
\hline - I feel agitate & & & & \\
\hline$\square$ Very low & $\square$ Low & $\square$ High & $\square$ Too high & \\
\hline - I am concer & out advers & & & \\
\hline$\square$ Very low & $\square$ Low & $\square$ High & $\square$ Too high & \\
\hline - I feel satisfa & & & & \\
\hline$\square$ Very low & $\square$ Low & $\square$ High & $\square$ Too high & \\
\hline - I feel fear. & & & & \\
\hline$\square$ Very low & $\square$ Low & $\square$ High & $\square$ Too high & \\
\hline - I feel comfo & & & & \\
\hline$\square$ Very low & $\square$ Low & $\square$ High & $\square$ Too high & \\
\hline - I'm confide & & & & \\
\hline$\square$ Very low & $\square$ Low & $\square$ High & $\square$ Too high & \\
\hline - I upset my 1 & & & & \\
\hline$\square$ Very low & $\square$ Low & $\square$ High & $\square$ Too high & \\
\hline
\end{tabular}




\begin{tabular}{|c|c|c|c|c|c|}
\hline \multicolumn{6}{|c|}{ Dental Anxiety Inventory: } \\
\hline \multicolumn{6}{|c|}{ Please determine the best option that describes your feeling with the cross mark. } \\
\hline \multicolumn{6}{|c|}{ - I feel restless. } \\
\hline$\square$ Very low & $\square$ Low & $\square$ High & $\square$ Too high & & \\
\hline \multicolumn{6}{|c|}{ - I cannot decide. } \\
\hline$\square$ Very low & $\square$ Low & $\square$ High & $\square$ Too high & & \\
\hline \multicolumn{6}{|c|}{ - My physical comfort. } \\
\hline$\square$ Very low & $\square$ Low & $\square$ High & $\square$ Too high & & \\
\hline \multicolumn{6}{|c|}{ - I feel that I am convinced. } \\
\hline$\square$ Very low & $\square$ Low & $\square$ High & $\square$ Too high & & \\
\hline \multicolumn{6}{|c|}{ - I am concerned. } \\
\hline$\square$ Very low & $\square$ Low & $\square$ High & $\square$ Too high & & \\
\hline \multicolumn{6}{|c|}{ - I confusing thoughts. } \\
\hline$\square$ Very low & $\square$ Low & $\square$ High & $\square$ Too high & & \\
\hline \multicolumn{6}{|c|}{ - I feel I am consistent. } \\
\hline$\square$ Very low & $\square$ Low & $\square$ High & $\square$ Too high & & \\
\hline \multicolumn{6}{|c|}{ - I am refreshed and recharged. } \\
\hline$\square$ Very low & $\square$ Low & $\square$ High & $\square$ Too high & & \\
\hline \multicolumn{6}{|c|}{ Patient satisfaction survey: } \\
\hline \multicolumn{6}{|c|}{ - Do you have a conversation with the doctor comfort? } \\
\hline$\square$ Very high & $\square$ High & $\square$ Low & $\square$ Slightly satisfied & $\square$ Not satisfied & $\square$ Other reasons \\
\hline \multicolumn{6}{|c|}{ - Do you how to answer questions related to the problem you were satisfied? } \\
\hline$\square$ Very high & $\square$ High & $\square$ Low & $\square$ Slightly satisfied & $\square$ Not satisfied & $\square$ Other reasons \\
\hline \multicolumn{6}{|c|}{ - Is the overall communication of the examination and doctor were satisfied? } \\
\hline$\square$ Very high & $\square$ High & $\square$ Low & $\square$ Slightly satisfied & $\square$ Not satisfied & $\square$ Other reasons \\
\hline \multicolumn{6}{|c|}{ - Do you think you better check for changes in the method of examination and physician need? } \\
\hline$\square$ No & $\square$ Yes & & & & \\
\hline \multicolumn{6}{|c|}{ Patient Anxiety Inventory } \\
\hline \multicolumn{6}{|c|}{ - If you dentist and make an appointment for tomorrow what you feel? } \\
\hline$\square$ No anxiety & $\square$ Mild anxiety & $\square$ Average anxiety & $\square$ High anxiety & $\square$ Very high anxiety & \\
\hline \multicolumn{6}{|c|}{ - Imagine you are sitting and waiting room Dental're definitely doing it later how do you feel? } \\
\hline$\square$ No anxiety & $\square$ Mild anxiety & $\square$ Average anxiety & $\square$ High anxiety & $\square$ Very high anxiety & \\
\hline \multicolumn{6}{|c|}{ - Imagine that your dentist is cutting teeth to be filled. How do you feel? } \\
\hline$\square$ No anxiety & $\square$ Mild anxiety & $\square$ Average anxiety & $\square$ High anxiety & $\square$ Very high anxiety & \\
\hline \multicolumn{6}{|c|}{ - Imagine that your dentist scaling and polish the teeth, how you feel? } \\
\hline$\square$ No anxiety & $\square$ Mild anxiety & $\square$ Average anxiety & $\square$ High anxiety & $\square$ Very high anxiety & \\
\hline \multicolumn{6}{|c|}{ - Imagine that one of the posterior teeth in the gums dentist will inject anesthesia you, how you feel? } \\
\hline$\square$ No anxiety & $\square$ Mild anxiety & $\square$ Average anxiety & $\square$ High anxiety & $\square$ Very high anxiety & \\
\hline
\end{tabular}

Table 1: Used questioners

The last year students had three adult patients for comprehensive treatment program. They had to do dental procedures on them at least in three wards of the following wards: surgery, endodontics, reparative dentistry, periodontics or prosthodontics. The students learnt how to fill the questionnaires and they instructed their patients how to do it. The questionnaires were collected and because of ethic principles, participants were identified with numeric codes. Data were analyzed with t-test and Pearson correlation coefficient.

\section{Results}

Students were divided into two groups: experimental and control. Results of descriptive evaluation are presented in Table 2. 


\begin{tabular}{|l|l|l|l|l|l|}
\hline Group & N & Min & Max & Mean & Std Deviation \\
\hline Mean value of student anxiety & 51 & 2.15 & 4.00 & 3.12 & 0.40 \\
\hline Mean value of student satisfaction & 51 & 2.75 & 4.75 & 3.76 & 0.46 \\
\hline Mean value of patient satisfaction & 153 & 3.00 & 5.00 & 4.23 & 0.42 \\
\hline Mean value of patient anxiety & 153 & 2.53 & 4.50 & 3.44 & 0.50 \\
\hline
\end{tabular}

P-value for experimental group was 0.489 and for control group was 0.764 then data were normal and a t-test was used to analyze data. $(\mathrm{p}=0.05)$

Table 2: Statistics indicators of satisfaction and anxiety between students and patients

\begin{tabular}{|l|l|l|l|l|l|l|}
\hline Group & $\mathbf{N}$ & Mean & Std Deviation & Std Error & Df & P-Value \\
\cline { 1 - 5 } Interventional & 19 & 3.5789 & 0.40870 & 0.09376 & \multirow{2}{*}{$0 / 024^{\star}$} \\
\cline { 1 - 3 } & 31 & 3.8790 & 0.46039 & 0.08269 & & \multirow{2}{*}{0} \\
\hline
\end{tabular}

*There was a significant difference between satisfaction of interventional and control group. The communication skills workshop increased satisfaction of dental students

Table 3: Mean analysis of students' satisfaction score

There was no significant difference between patients satisfaction in the experimental and control group ( $\mathrm{p}$-value $=0.125)$.

There was no significant differences between patients' anxiety in the experimental and control group $(\mathrm{p}$-value $=0.750)$.

There was no significant differences between students anxiety in the experimental and control group $(\mathrm{p}$-value $=0.770)$.

Mean analysis of students' satisfaction score was presented in Table 3.

To evaluate the relationship between anxiety and satisfaction, a Pearson correlation coefficient was used. There was a negative correlation between anxiety and satisfaction ( $\mathrm{p}$-value $=0.030, \mathrm{r}=0.305)$.

\section{Discussion}

Being able to recognize fear and anxiety in dental patients is an important part of overall patient management. Knowledge of various behavior management techniques, and the use of less-invasive operative techniques, enables the clinician to treat a large proportion of anxious people and help them to cope with dental treatment in the primary care setting [11]. It has been proved learning doctor-patient relationship skills is essential $[12,13]$. Fear and anxiety in dentistry had adverse effects on satisfaction of patient and doctor. Studies show the less anxiety, the more satisfaction [14]. One of the most important considerations in the decrease of anxiety is good communication between patient and doctor [1,4,15]. Ghasempur and Haddadi [16] in evaluation of anxiety level in dental and medical students in Babol University used Dental Anxiety Scale (DAS) questionnaires and reported mean value of $8.03 \pm 3.73$ for students' anxiety. We used DAS for evaluation of patients' anxiety and mean value for patients anxiety was 3.44 and for students' anxiety was 3.12. Anxiety levels in our survey were less than those of Ghasemi, et al. A study by Emadzadeh, et al. showed that improvement of communication skills increases patients satisfaction and they suggested that communication skills workshops can be beneficial $[17,18]$. In our survey, communication skills workshop increased the satisfaction of students but there was no effect on patients' satisfaction. It seems that ethnic and cultural differences of patients and short duration of the course and the small sample size and the fact that it was selected only certain patients referred to the clinic were the reasons for the lack of influence of teaching communication skills patient doctor on increase patient satisfaction and reduce their anxiety. In addition, ggeneral education based on the culture of each society would be helpful to relieve their anxiety in dental visits which is the responsibility of policymakers in each country. Razmi and Talari evaluated satisfaction of patients who referred to dental faculty of Tehran University. 83.3 percent of patients were satisfied. In that study, patients' satisfaction among the other variables was at the maximum quantity [19]. However dental anxiety and fear are common and potentially problematic, both for the patient and for the dental team in managing such patients. Furthermore, dental fear still presents a major barrier to the uptake of dental treatment. In commissioning and developing dental services due consideration should be given to addressing the needs of all patients with dental anxiety [20]. In this study there was a significant negative correlation between anxiety and satisfaction in both dental students and their patients. Communication skills increased the students' satisfaction, had an indirect effect on their anxiety level, and decreased it. Communication skills workshop is useful at least for dental students and would have good effects on doctor-patient correlation.

\section{The implication of the study}

According to this study results, holding workshops for promoting doctor-patient communication skills can lead to in-crease in doctor's satisfaction and decline in doctor's anxiety, hence having these kinds of workshops should be includ-ed in the curriculum of dentistry.

\section{Acknowledgement}

The authors would like to thank the research council of the Mashhad University of Medical Sciences which financially supported this study (protocol code 88455, Dental student thesis 2201)

\section{References}

1. Dionne RA, Yagiela JA, Moore PA, Gonty A, Zuniga J, et al. (2001) Comparing efficacy and safety of four intrave-nous sedation regimens in dental outpatients. J Am Dent Assoc 132: 740-51. 
2. Kleinknecht RA, Klepac RK, Alexander LD (1973) Origins and characteristics of fear of dentistry. J Am Dent Assoc 86: 842-8.

3. McGlynn FD, Bichajian C, Giesen JM, Rullan CM, Pulver L (1981) Factorial study of component procedures in de-sensitization treatment of test anxiety among college students. Psychol Rep 49: 351-62.

4. Frere CL, Crout Ri, Yorty J, McNeil DW (2001) Effects of audiovisual distraction during dental prophylaxis. J Am Dent Assoc 132: 1031-8.

5. Doebling S, Rowe MM (2000) Negative perceptions of dental stimuli and their effects on dental fear. J Dent Hyg 74: 110-6.

6. Mataki S (2000) Patient-dentist relationship. J Med Dent Sci 47: 209-14.

7. Erten H, Akarslan ZZ, Bodrumlu E (2006) Dental fear and anxiety levels of patients attending a dental clinic. Quin-tessence Int 37: 304-10.

8. Veldhuis B, Schouten BC (2003) The relationship between communication styles of dentists and the satisfaction of their patients. Ned Tijdschr Tandheelkd 110: 387-90.

9. Schouten BC, Eijkman MA, Hoogstraten J (2003) Dentists' and patients' communicative behaviour and their satisfaction with the dental encounter. Community Dent Health 20: 11-5.

10. Armfield JM, Heaton LJ (2013) Management of fear and anxiety in the dental clinic: a review. Aust Dent J 58: 390-407.

11. Rafique S, Banerjee A, Fiske J (2008) Management of the petrified dental patient. Dent Update 35: 196-8, 201-2, 204 passim.

12. Schouten BC, Hoogstraten J, Eijkman MA (2003) Patient participation during dental consultations: the influence of patients' characteristics and dentists' behavior. Community Dent Oral Epidemiol 31: 368-77.

13. DuRant RH, Pierce KL, Powell BJ, Sanders JM (1989) Dentists' professional satisfaction with adolescent dentistry and its association with adolescent dental health behavior. J Adolesc Health Care 10: 46-50.

14. Shugars DA, Hays RD, DiMatteo MR, Cretin S (1991) Development of an instrument to measure job satisfaction among dentists Med Care 29: 728-44.

15. Gorter RC (2005) Work stress and burnout among dental hygienists. Int J Dent Hyg 3: 88-92.

16. Ghasempur M, Haddadi A (2006) Study of the amount of fear and anxiety level of dental and medical students in Babol University of medical science. Islamic Dental Association of Iran 17: 9-14.

17. Emadzadeh A, Yavari M, Ebrahimzadeh S (2005) Study of dental residents' communication skills and its effect on patients' satisfaction in Mashhad University of medical science. Mashhad Dental School J 35: 69-76.

18. Lloid M, Bor R (2002) Communication skills for Medicine 5th ed, London. Churchill Livingstone 169-70.

19. Razmi H, Talari M (2006) Study of satisfaction level of patients of Tehran dental school in 1382. Islamic Dental Assoc of Iran 17: 82-9.

20. Newton T, Asimakopoulou K, Daly B, Scambler S, Scott S (2012) The management of dental anxiety: time for a sense of proportion?. Br Dent J 213: 271-4.

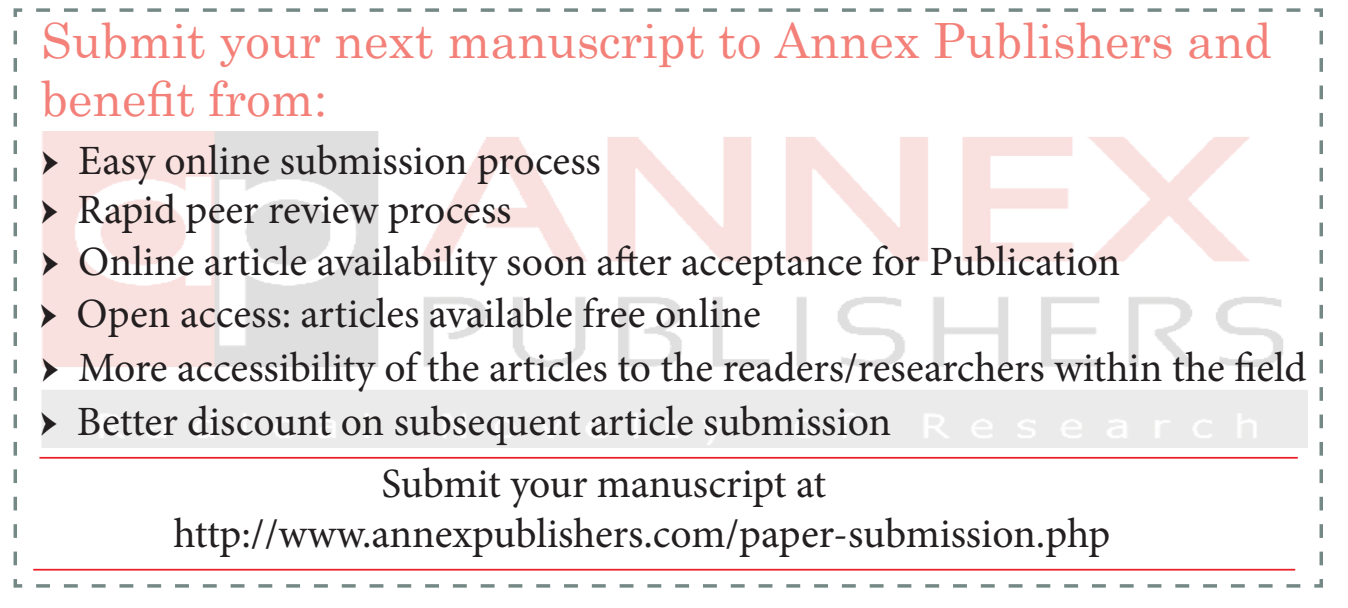

